\title{
Kurikulum 2013 di Madrasah Ibtidaiyah: Implementasi di Wilayah Minoritas Muslim
}

\author{
Ismail Suardi Wekke ${ }^{1}$, Ridha Windi Astuti ${ }^{2}$ \\ ${ }^{1,2}$ Sekolah Tinggi Agama Islam Negeri (STAIN) Sorong; iswekke@gmail.com \\ Diterima: 4 Maret 2017. Disetujui: 22 Mei 2017. Dipublikasikan: Juni 2017
}

\begin{abstract}
The curriculum has a very important role in the educational process. In Indonesia, the curriculum had changed in several times, including: Kurikulum 1994, Kurikulum Berbasis Kompetensi (KBK) in 2004, Kurikulum Tingkat Satuan Pendidikan (KTSP), and Kurikulum 2013. The focus of this research, is in the implemetation the curriculum 2013 in Muslim minority areas. The Implementation of the curriculum 2013 at MIN Cempaka Putih Jakarta and West Papua Malawele partly already implemented properly and in accordance with the objectives of the curriculum in 2013. The change of the teacher's role as a motivator and facilitator already visible. Where in learning the Arabic language teachers give students to be more able exploring earning materials and teachers have also begun to embed a variety of character education as a team-based learning.
\end{abstract}

\begin{abstract}
Abstrak
Kurikulum memiliki peranan yang sangat penting dalam proses pendidikan. Kurikulum di Indonesia pernah beberapa kali mengalami perubahan, diantaranya: Kurikulum 1994, Kurikulum Berbasis Kompetensi (KBK) 2004, Kurikulum Tingkat Satuan Pendidikan (KTSP), dan Kurikulum 2013. Fokus penelitian pada kurikulum 2013 yang di Implementasikan di wilayah minoritas muslim. Implementasi kurikulum 2013 di MIN Cempaka Putih Jakarta dan MIN Malawele Papua Barat sebagian sudah terlaksana dengan baik dan sesuai dengan tujuan kurikulum 2013. Pergantian peran guru sebagai motivator dan fasilitator sudah terlihat. Dimana dalam pembelajaran bahasa arab guru memberikan siswa agar lebih mampu mengekspolarasi materi pembelajaran dan guru juga sudah mulai menanamkan berbagai pendidikan karakter seperti pembelajaran berbasis tim.
\end{abstract}

Kata kunci: kurikulum 2013, implementasi, wilayah minoritas islam.

(C) 2017 URPI, FTK IAIN Raden Intan Lampung

\section{PENDAHULUAN}

Pendidikan menjadi media yang mempunyai pengaruh untuk menentukan arah kesuksesan negara (Listiyani \& Widayati, 2012; Sulthon, 2014). Pendidikan menjadi pilar dalam upaya pengembangan sumber daya manusia (Marlina, 2013; Sauri, n.d.). Seiring perkembangan, kurikulum mengalami perubahan demi perubahan sebagai respon atas kondisi saat ini.

Bahasa arab merupakan bahasa yang digunakan dalam Al-Quran dan sudah menjadi bagian dari pembelajaran keagamaan dalam islam (Ayuba, 2012). Sehingga pilihan mengembangkan bahasa arab sudah menjadi keharusan dan tuntutan tersendiri. Kemampuan bahasa menjadi elemen yang sangat penting dalam kehidupan (Zulkifli, 2014). Pola pembelajaran yang terprogram akan mendorong motivasi dan kreativitas siswa dalam berbahasa (Wekke, 2011). Salah satu cara membuat pembelajaran berbahasa arab dengan terprogram adalah dengan cara mengikuti kurikulum yang berlaku.

Kurikulum memiliki peranan yang sangat penting dalam proses pendidikan (Çubukçu, 2012). Pada kurikulum membahas bagaimana dan tentang apa pendidikan tersebut dilaksanakan (Ibrahim, 2014). Oleh karena itu, seiring dengan perkembangan kurikulum dari waktu ke waktu seseorang pendidik harus memahami dan mengimplementasikan 
kurikulum dengan baik. Kurikulum di Indonesia pernah 11 kali mengalami perubahan, diantaranya: Kurikulum tahun 1947, kurikulum tahun 1964 (Rencana Pendidikan Sekolah Dasar), kurikulum tahun 1968 (Kurikulum Sekolah Dasar), kurikulum tahun 1973 (Kurikulum Proyek Perintis Sekolah Pembangunan/PPSP), kurikulum tahun 1975 (Kurikulum Sekolah Dasar), umkurikulum tahun 1984 (Kurikulum 1984), kurikulum tahun 1994 (Kurikulum 1994), kurikulum 1997 (Revisi Kurikulum 1994), kurikulum 2004 (Rintisan Kurikulum Berbasis Kopemtensi/KBK), kurikulum 2006 (Kurikulum Tingkat Satuan Pendidikan/KTSP) dan yang terakhir kurikulum 2013 (Qomariyah, 2014).

Dalam penetapan sebuah kurikulum, maka beberapa langkah yang harus dilakukan. Sebuah model bagi pengembangan kurikulum yaitu salah satunya adalah interative curriculum discourse analysis (ICDA) (Iversen, 2014). Analisis struktural tujuh langkah praktis. Termasuk menggabungkan tiga hal yaitu keagamaan, identitas, dan nilai yang berkembang di masyarakat. Sebagai contoh pengembangan kurikulum dengan model ini di tetapkan di Norwegia .

Kementrian kebudayaan RI melakukan berbagai upaya untuk meningkatkan pembangunan dan kualitas pendidikan di Indonesia (Albantani, 2015), salah satu caranya adalah mengembangkan kurikulum pendidikan nasional yaitu kurikulum 2013 yang mulai di implementasikan secara bertahap mulai tahun pelajaran 2013-2014 melalui pelaksanaan terbatas, khususnya bagi sekolah-sekolah yang sudah siap melaksanakanya. Pada tahun pelajaran 2013/2014 kurikulum 2013 di gunakan secara terbatas untuk kelas I-IV di Madrasah Ibtidayyah (MI) (Ekawarna, 2013).

Kurikulum yang digunakan dalam pembelajaran bahasa arab sebelumnya belum mampu mengoptimalkan pembelajaran bahasa arab di Madrasah
Ibtidaiyah terutama kelas rendah. Secara teoritis, ada dua masalah yang sering di jumpai dalam pembelajaran bahasa arab, yaitu masalah kebahasaan yang sering di sebut linguistic, dan masalah non kebahasaan atau non-linguistic (Rohman, 2014).

Selain 2 (dua) masalah tersebut akhir-akhir ini pembelajaran bahasa arab mengalami sedikit kemunduran, yang mana pembelajaran yang di ajarkan monoton sehingga tidak menarik minat peserta didik untuk mempelajari bahasa arab (Fahrurrozi \& Mahyudin, 2012; Rohman, 2014). Untuk itu, pemerintah berusaha mengganti kurikulum pembelajaran dari KTSP menjadi K13 dengan harapan pembelajaran bahasa arab lebih fleksibel dan mampu membuat siswa lebih berkembang.

Penelitian pendidikan Islam selama ini masih berada dalam arus utama dalam konteks muslim mayoritas. Untuk itu fokus penelitian ini mengimplementasikan kurikulum 2013 dalam konteks muslim minoritas (Adawiyah \& Jamaluddin Z, 2016).

\section{METODE PENELITIAN}

Metode penelitian yang digunakan dalam penelitian ini adalah deskriptif kualitatif. Dengan tekhnik pengumpulan data yang digunakan melalui observasi dan wawancara.

\section{HASIL DAN PEMBAHASAN \\ Penerapan Kurikulum di MIN Malawele}

Saat ini kurikulum 2013 memang sudah mulai digunakan termasuk sekolahsekolah yang berada di bawah naungan Departemen Agama. Kurikulum 2013 sendiri dijalankan bukan tanpa hambatan. Sejak awal kurikulum ini digunakan telah memunculkan perbedaan pandangan dari kalangan masyarakat, anara pro dan kontra. Meskipun sama-sama menggunakan kurikulum 2013 terdapat perbedaan dalam pengaplikasiaan seperti di MIN Cempaka Putih Jakarta dan di 
MIN Malawele, Papua Barat. Pembelajaran bahasa arab di MIN Malawele menggunakan dua buku yaitu buku Pembelajaran Bahasa Arab dan buku terbitan Erlangga dengan pola KTSP 2006. Dimana, dalam pembelajaran bahasa Arab siswa kelas 1-3 diwajibkan menguasai 8-10 kosakata dalam setiap materi, sedangkan kelas 4-6 ditargetkan menguasai 20 kosakata dalam setiap materi. Pembelajaran ini berlangsung secara berlanjut dengan cara guru memberikan latihan kepada siswa agara bisa menggunakan kosakata yang telah di hafal baik di aplikasikan dalam bentuk lisan maupun tulisan. Setiap akhir semester guru biasanya meminta siswa untuk menghafal semua kosakata yang telah dihafalnya untuk di setor ke guru mata pelajaran bahasa arab.

Dalam proses pembelajaran guru menggabungkan beberapa metode yang di anggap sesuai dengan kondisi di kelas dengan menggunakan metode komunikatif. Dalam pembelajaran bahasa arab di MIN Malawele siswa diberikan latihan untuk memahami suatu bacaan. Ini didukung dengan adanya pembelajaran baca tulis Al-Quran yang telah di terapkan sejak kelas rendah. Dengan kemampuan membaca Al-Quran dengan baik, akan mempermudah murid dalam mengikuti pembelajaran bahasa arab.

Dari segi standar kompetensi lulusan, sekitar 60-70 \% terdapat pada mata pelajaran bahasa Arab. Dari segi perubahan kurikulum, kurikulum 2013 dalam pembelajaran bahasa arab khususnya di kelas I, II, dan III, bukan di tekankan pada menulis tetapi lebih pada menyimak, mendegar, meniru dan megetahui bahasa arab dari objek yang ada pada gambar. Guru selalu memulai dan menutup kelas dengan menggunakan bahasa arab guna membiasakan siswa mengguakan bahasa arab terutama kosakata yang dipelajari untuk digunakan sebagai alat komunikasi. Berikut beberapa perbedaan dalam pengaplikasiaan kurikulum 2013 di MIN Cempaka Putih
Jakarta dan MIN Malawele Sorong Papua Barat:

1. Kegiatan tak selalu berpusat kepada peserta didik

Guru terkadang harus membimbing peserta didik terlebih dahulu, peserta didik yang kurang aktif dan rasa ingin tahunya yang masih kurang sehingga guru harus lebih berusaha memotivasi siswa agar mau mencari tahu.

2. Kegiatan pembelajaran bersifat interaktif

Guru tidak menggunakan metode langsung, sehingga dalam komunikasi guru masih menggunakan $70 \%$ bahasa Indonesia dan $30 \%$ bahasa arab untuk di kelas tinggi 4-6. Sedangkan untuk kelas rendah siswa hanya sebatas meniru, namun dalam perintah dan arahan guru sudah menggunakan bahasa arab namun setelah itu di terjemahkan lagi kedalam bahasa Indonesia.

3. Kegiatan pembelajaran berbasis lingkungan

Terkadang pembelajaran bahasa arab dilakukan di luar kelas sekitar halaman maupun lapangan sekolah jika materinya bertema tentang lingkungan namun pembelajaran lebih sering berlangsung di dalam kelas. Sekolah juga belum memiliki labortorium bahasa sehingga untuk praktik mendengar atau menyimak guru hanya menggunakan ruang kelas dan speaker yang di hubungkan ke leptop.

4. Kegiatan pembelajaran bersifat aktif menyeledidki

Siswa di berikan keluasan untuk bertanya dan mengekspor tentang materi bahasa arab. Namun karena tingkat rasa ingin tahu yang rendah siswa harus terlebih dahulu di berikan kuis baru mau berusaha mencari tahu.

5. Kegiatan pembelajaran menggunakan konteks dunia nyata

Guru menggunakan peristiwa seharihari yang sering terjadi pada kehidupan siswa yang nantinya di 
kaitkan dengan pembelajaran bahasa arab agar siswa lebih mudah memahami dan menghafal kosakata.

6. Kegiatan pembelajaran berbasis Tim Untuk menyelesaikan sebuah tugas biasanya guru meminta siswa membuat kelompok yang berisikan 45 anggota. Untuk kelas rendah biasanya hanya sekedar mencocokan gambar dan tulisan, kelas tinggi biasanya untuk membuat suatu teks percakan yang nantinya diperagakan di depan kelas. Pekerjaan tim seperti ini diharapkan dapat menumbuhkan rasa kepedulian terhadap sesama dan juga melatih rasa percaya diri siswa menyampaikan pendapatnya di dalam sebuah tim dan nantinya akan di pertanggungjawabkan di depan kelas.

7. Menggunakan berbagai metode yang menarik minat anak terhadap bahasa. Guru sering menerapkan beberapa metode, seperti untuk anak di kelas satu guru menggunakan metode nyanyian agar anak lebih mudah memahami dan menghafal kosakata, untuk di kelas tinggi guru menggunakan metode snowball, arisan, kerja tim dan masih banyak lagi.

8. Kegiatan pembelajaran menggunakan alat multimedia. Walaupun tidak ada lab bahasa di MIN Malawele, guru biasanya menggantikannya dengan media powerpoint, benda-benda yang ada di kelas, lagu-lagu, dan biasanya ada perlombaan bahasa arab di bulan bahasa, perlombaanya meliputi membaca puisi menggunakan bahasa arab, membuat poster kosakata bahasa arab.

9. Penggunaan kurikulum 2013 yang belum stabil. Perubahan kurikulum yang belum serentak menyebabkan sekolah ini khususnya dalam mata pelajaran bahasa arab masih menggunakan kurikulum yaitu KTSP untuk siswa yang duduk di bangku kelas 6 dan kurikulum 2013 dikelas $1-5$.
Adapun perbedaan penerapan kurikulum 2013 di kedua sekolah yaitu MIN Cempaka Putih Jakarta sudah serentak menggunakan kurikulum 2013 sedangkan di MIN Malawele tidak semua kelas menggunakan kurikulum 2013. Rasa ingin tahu siswa di lingkungan MIN Cempaka putih sangat besar sehingga MIN Cempaka putih sudah bisa dijadikan sebagai contoh keberhasilan penerapan kurikulum 2013. Sedangkan di MIN Malawele sikap tak acuh siswa yang masing begitu tinggi membuat guru harus lebih inovatif dan kritis dalam menggunakan berbagai pendekatan. Di MIN Malawele sangat nampak peran guru masih dominan, sedangkan siswa belum bisa menjadi pusat. Selain itu, juga faktor sarana prasarana yang belum memadai sehingga guru harus menggunakan alat seadanya untuk menyelesaikan sebuah pembahasan dalam sebuah materi.

Berdasarkan beberapa jurnal telah menggambarkan dan menjelaskan mengenai implementasi kurikulum 2013 di MI yang ada di Jakarta dan yang ada di Papua Barat, yang mana kurikulum 2013 ini sudah sangat baik. Hal ini merupakan sebuah barometer semakin baiknya pendidikan di Indonesia. Kurikulum ini hadir di saat gersangnya dunia penididikan akibat makin maraknya pendidikan yang hanya mampu mencerdaskan peserta didik tanpa memperhatikan aspek moral dan nilainilai luhur bangsa kita. Kurikulum ini mengakomodir pembelajaran yang berbasis karakter. Dimana, peserta didik tidak hanya pintar namun mempunyai karakter yang sesuai dengan bangsa Indonesia. Dalam kurikulum ini memuat semua aspek yang ingin dicapai oleh lima sila negara Indonesia dengan pembelajaran menerapkan unsur ketuhanan, kemanusiaan, peduli terhadap sesama, dan juga jati diri bangsa.

Kurikulum ini hadir sebagai sebuah jawaban tanatangan zaman yang dibuat untuk menyempurnakan kurikulum- 
kurikulum yang sudah ada. Sebenarnya kurikulum ini tidak terlalu berbeda dengan kurikulum yang apa pada sebelumnya seperti Kurikulum 1994, KBK, dan KTSP. Kurikulum 2013 hasil dari kombinasi dan komparasi kurikulum sebelumnya, perbedaanya terletak pada banyaknya metode dan teknik yang ditawarkan dalam sebuah pembelajaran di kurikulum baru ini. Namun sayangnya, persiapan yang belum begitu matang menyebabkan kurikulum ini seperti kurikulum yang tidak pasti, kurikulum ini sempat digenjot untuk digunakan pada tahun pelajaran yang lalu, namun belum juga cukup satu semester pemerintah memerintahkan untuk kembali menggunakan KTSP dikarenakan belum siapnya lembaga yang terkait untuk menggunakan kurikulum ini. Hal inilah yang menyebabkan banyak sekolah bingung dalam menggunakan sebuah kurikulum. Akhirnya pemerintah menetapkan bagi sekolah yang telah terlanjur menggunakan kurikulum 2013 untuk tetap menggunakanya dan yang belum kembali menggunakan KTSP.

Dalam rangka membuat dan mendistribusikan sebuah kurikulum bukanlah hal yang mudah dan murah. Sudah banyak anggaran negara yang di gunakan untuk mendistribuskan kurikulum ini belum lagi ditambah banyaknya kerugian yang harus di tanggung oleh penerbit buku yang telah menerbitkan banyak buku pelajaran yang berbasis kurikulum 2013. Memang pada dasarnya, bukanlah hal yang mudah untuk mengganti sesuatu dengan yang baru, apalagi jika itu menyangkut sebuah sistem maka semua lapisan harus siap berbenah diri dan memulai dari nol. Begitu dengan kurikulum, banyak guru dan masyarakat yang mengeluh karena kurikulum menyulitkan guru dan membingungkan orang tua. Sebenaranya hal ini terjadi karena masih kurangnya informasi dan sosialisasi.

Meskipun saat ini masih belum jelas kurikulum yang digunakan, penulis sangat berharap bahwa kurikulum 2013 dapat di gunakan di seluruh Indonesia dengan serentak karena sangat tepat dan sesuai dengan tujuan bangsa Indonesia yaitu pendidikan yang berkarakter. Selain itu juga kurikulum ini memberikan keleluasaan guru dalam menilai. Guru menilai dengan objektif, namun tidak hanya berpatokan kepada aspek kognitif siswa melainkan menilai dari semua aspek. Selain itu kelebihan kurikulum ini bagi siswa adalah siswa diberikan kebebasan untuk berkembang, mempermudah mendeteksi minat dan bakat, melakukan sesuai dengan apa yang mereka ketahui, dan siswalah menjadi objek pusat perhatian dalam sebuah kelas.

Sampai saat ini masih banyak guru yang mengeluh rumitnya sistem penilaian yang ditawakan dari kurikulum 2013, yang mana guru harus menilai setiap perkembangan anak dan menjabarkan setiap penilaian di buku rapor siswa. Namun disisi lain, tetap yakin akan hal ini karena masih kurangnya pengetahuan guru dan belum terbiasa dalam penerapannya. Jika semakin seringnya sosialisasi penggunaan kurikulum 2013 ini dilaksanakan sehingga guru sudah mulai terbiasa, maka tujuan pendidikan akan lebih mudah dicapai khususnya dalam pembelajaran bahasa arab sendiri di MIN Malawele. Adapun rasionalitas penyebab belum bisa menerapkan kurikulum 2013 terutama dalam aspek utama yaitu mengubah siswa dari subjek pembelajaran menjadi objek pembelajaran secara maksimal dikarenakan banyak faktor, diantaranya :

1. Kompleksitas bahasa arab

Karakteristik bahasa arab yang kompleks dan rumit sehingga menimbulkan tantangan serius bagi pembelajarnya.

2. Lingkungan dan fasilitas pembelajaran

Lingkungan minoritas muslim di sekitar MIN Malawele membuat siswa kesulitan untuk menyalurkan materi yang didapatnya dari sekolah, 
sehingga materi yang mereka dapat hanya mampu mereka kuasai untuk waktu yang singkat. Fasilitas yang belum memadai juga membuat proses pembelajaran kurang maksimal.

3. Metode pembelajaran bahasa arab Metode yang digunakan dalam pembelajaran bahasa arab sangat tergantung dari prinsip dan konsep yang dipahami oleh seorang guru atau pendidik terhadap suatu bahasa. Baik metode konvensional (tradisonal) maupun inkonvensional (modern atau inovatif), keduanya memiliki kelebihan dan kekurangan. Untuk itu seorang guru atau pendidik bahasa arab harus jeli melihat aspek positif dan negatif dari kedua metode tersebut.

4. Guru sebagai faktor motivasi terbesar bagi peserta didik

Kurangnya motivasi dapat menyebabkan guru kurang berhasil dalam mengajarkan bahasa asing. Faktor kepribadian dan perilaku menjadi salah satu pemicu berhasil tidaknya suatu pembelajaran.

Adapun beberapa hambatan yang dimaksud dalam konteks ini, diantaranya:

1. Informasi yang diterima tentang pengembangan kurikulum 2013 di sekolah tidak utuh, sehingga guru dan sekolah belum memahami secara penuh pelaksaan kurikulum 2013 tersebut.

2. Pembinaan bagi sekolah dari dinas pendidikan dalam implementasi kurikulum 2013 tidak lengkap. Hal ini terlihat antara lain guru belum memahami masalah life skill.

3. Jumlah rombongan belajar terlalu padat (40 orang perkelas) hal ini menyebabkan guru kesulitan dalam mengelola kelas dan penilaian berbasis kemampuan dasar khususnya dalam mengatur performance dan psikomotor siswa.

\section{SIMPULAN DAN SARAN}

Implementasi kurikulum di Implementasi kurikulum 2013 di MIN Cempaka Putih Jakarta dan MIN Malawele Papua Barat sebagian sudah terlaksana dengan baik dan sesuai dengan tujuan kurikulum 2013. Pergantian peran guru sebagai motivator dan fasilitator sudah terlihat. Dimana dalam pembelajaran bahasa arab guru memberikan siswa agar lebih bisa mengekspolarasi materi pembelajaran dan guru juga sudah mulai menanamkan berbagai pendidikan karakter seperti pembelajaran berbasis tim.

\section{DAFTAR PUSTAKA}

Adawiyah, R., \& Jamaluddin Z, W. (2016). Rekayasa Pendidikan Agama Islam di Daerah Mnoritas Muslim. Tadris:Jurnal Keguruan Dan Ilmu Tarbiyah, 1(2), 119-132. Retrieved from

http://ejournal.radenintan.ac.id/index .php/tadris

Albantani, A. M. (2015). Implementasi Kurikulum 2013 pada Pembelajaran Bahasa Arab Di Madrasah Ibtidaiyah. Arabiyat, 2(2), 178-191. https://doi.org/http://dx.doi.org/10.15 408/a.v2i2.2127

Ayuba, M. A. (2012). The Arabic Language: Its Relevance to Nigerian Development. European Scientific Journal, 8(26), 192-202.

Çubukçu, Z. (2012). The Effect of Hidden Curriculum on Character Education. Educational Sciences: Theory \& Practice, 12(2), 1526-1534.

Ekawarna. (2013). Pemahaman Guru SD tentang Implementasi Kurikulum 2013. Jurnal Cerdas Sifa Pendidikan, 1(2).

Fahrurrozi, A., \& Mahyudin, E. (2012). Pembelajaran Bahasa Arab. Jakarta: Direktorat Jenderal Pendidikan Islam Kementerian Agama.

Ibrahim, A. (2014). Tujuan Pendidikan 
Dalam Aspek Kurikulum Indonesia. Islamic StudiesJournal, 2(1), 174189.

Iversen, L. L. (2014). Presenting the iterative curriculum discourse analysis (ICDA). British Journal of Religious Education, 36(1), 53-71. https://doi.org/doi:http://dx.doi.org/1 0.1080/01416200.2013.830959

Listiyani, I. M., \& Widayati, A. (2012). Pengembangan Komik Sebagai Media Pembelajaran Akuntansi pada Kompetensi Dasar Persamaan Dasar Akuntansi untuk Siswa SMA Kelas XI. Jurnal Pendidikan Akuntansi Indonesia, X(2), 80-94.

Marlina, M. E. (2013). Kurikulum 2013 yang Berkarakter. JPIIS:Jurnal Pendidikan Ilmu-Ilmu Social, 5(2).

Qomariyah. (2014). Kesiapan Guru Dalam Menghadapi Implementasi Kurikulum 2013. Jurnal Pendidikan Ekonomi IKIP Veteran Semarang, 2(1), 21-35.

Rohman, F. (2014). Strategi Pengelolaan Komponen Pembelajaran Bahasa Arab. Arabiyat, 1(1), 63-78. https://doi.org/doi:10.15408/a.v1i1.1 131

Sauri, S. (n.d.). Strategi Pembanguanan Bidang Pendidikan untuk Mewujudkan Pendidikan Bermutu, 1-23.

Sulthon. (2014). Membangun Efikasi Diri untuk Meningkatkan Performansi Siswa Di Sekolah. ELEMENTARY, 2(2), 251-267.

Wekke, I. S. (2011). Motivasi Kreativitas, dan Presepsi Siswa dalam Efektivitas Berbahasa Arab (Survei di Madrasah Sekota Sorong). Jurnal Ilmiah Bahasa Dan Sastra Linguistika Academia, 1, 31-34.

Zulkifli, N. A. (2014). Meningkatkan Kemampuan Bahasa Inggris Siswa dengan Menggunakan Running Dictation melalui Materi Agama Di SD IT Al-Fittiyah Pekan Baru. Kutubkhanah: Jurnal Penelitian Sosial Keagamaan, 17(2), 175-197. 